\title{
CULTURAL HERITAGE DOCUMENTATION IN SIS ENVIRONMENT: AN APPLICATION FOR "PORTA SIRENA" IN THE ARCHAEOLOGICAL SITE OF PAESTUM
}

\author{
M. Pepe ${ }^{a^{*}}$, C. Parente ${ }^{\mathrm{a}}$ \\ a Department of Sciences and Technologies, University of Naples "Parthenope" Centro Direzionale, Isola C4, Naples, 80143, Italy \\ (massimiliano.pepe; claudio.parente)@uniparthenope.it
}

Commission WG V/1, WG V/2 WG II/8, WG VI/2

KEY WORDS: SIS, GIS, Close Range Photogrammetry, Cultural Heritage, Point Clouds.

\begin{abstract}
:
The Heritage Documentation allows the monitoring, maintenance and conservation by the most recent, efficient investigation techniques and storage of data. A key role in Heritage Documentation is represented by the Geographic Information Systems (GIS) and Spatial Information System (SIS), thanks to the possibility offered by this instrument not only to connect spatial elements (geographical features) to attribute tables, but also manage various information in the form of raster (terrestrial, aerial and satellite imagery), 3D point clouds, 3D models and other vector data.

The paper describes all the activities that lead to the construction of a SIS, especially in relation to the new survey technologies with particular focus at survey performed by Close Range Photogrammetry (CRP).

In addition, after explaining the relationships between the different information systems that contribute towards creating of a SIS and the various professions involved, a case study in Paestum area (Italy), showing the efficiency of Spatial Information System (SIS) technology, is discussed.
\end{abstract}

\section{INTRODUCTION}

In order to document the architectural of Cultural Heritage $(\mathrm{CH})$ environment, a GIS technology becomes important because this approaches allows to manage, within a georeferenced system, heterogeneous information produced at different stages of research and acquired in different ways (Hosse et al. 2003; Donadio et al., 2015; He et al., 2015). For Cultural Heritage applications of GIS technology, it is better to talk about Spatial Information Systems (SIS): usually local reference systems are used to locate the acquired data, so geographic coordinates can be used as ancillary information in order to locate the objects in a more general context. In other terms, SIS is a virtual space where each kind of information can refer a specific point in a known spatial reference system (Agosto et al., 2007).

Since the end of $80 \mathrm{~s}$, many authors have given several definitions of GIS and SIS (Burrough, 1986; Maguire, 1991; Hugo, 2000), regardless of the field of application. However, it is interesting to investigate the various components that connect the spatial information systems, and consequently the various skills that contribute to collect, store, interrogate, analyse, model, interpret and visualize spatially referenced information. The model of relationship between the GIS and other System Information proposed by Maguire (1991), can be write in a new relation in SIS environment, with particularly focus at field of Cultural Heritage. The various components and relationship that contribute to the formation of a SIS are: data acquisition, Archeological Database management, representation and maps (historical or less recent cartography).

\subsection{Data Acquisition by Close Range Photogrammetry}

The Data Acquisition is a subset of a SIS system, obtained by several survey and/or Remote Sensing techniques. Actually, a large number of Remote Sensing sensors are available for digital recording of Cultural Heritage. In general, optical recording sensors are divided in passive and active systems employed to derive 3D shapes and often referred to 3D imaging techniques (Gomarasca, 2009; Sansoni, 2009). Passive sensors deliver image data which are then processed with some mathematical formulations to infer $3 \mathrm{D}$ information from the $2 \mathrm{D}$ image measurements while active sensors can provide data directly for 3D information or ranges (Remondino, 2011). In last years, a passive remote sensing technique called Close Range Photogrammetry (CRP) is widespread due to ability to obtain, in a short time, accurate and detailed three-dimensional models. This technique use image correlation algorithms that identify the common points in photographs of the same object (Karara, 1989). By collinearity equations and in the more general context of the so-called bundle adjustment solution, several approaches are used in photogrammetry in order to determinate the unknown parameters. A popular approach that allows to estimate the unknown parameters (internal orientation, external orientation and object coordinates of points) is called self-calibration. The mathematical model of the bundle adjustment is (Grün et al., 2001):

$$
x_{i j}=-c_{j} \frac{r_{11 j}\left(X_{i}-X_{0 j}\right)+r_{21 j}\left(Y_{i}-Y_{0 j}\right)+r_{31 j}\left(Z_{i}\right.}{r_{13 j}\left(X_{i}-X_{0 j}\right)+r_{23 j}\left(Y_{i}-Y_{0 j}\right)+r_{33 j}(Z)}
$$




$$
y_{i j}=-c_{j} \frac{r_{12 j}\left(X_{i}-X_{0 j}\right)+r_{22 j}\left(Y_{i}-Y_{0 j}\right)+r_{32 j}(Z}{r_{13 j}\left(X_{i}-X_{0 j}\right)+r_{23 j}\left(Y_{i}-Y_{0 j}\right)+r_{33 j}(Z}
$$

where

$r_{i i j} \ldots r_{33 j}$ elements of the rotation matrix between image and object coordinate systems;

$X_{i}, Y_{i}, Z_{i}$

$X_{0 j}, Y_{0 j}, Z_{0 j}$

$x_{0 j}, y_{0 j}$

$x_{i j}, y_{i j}, 0$

$c_{j}$

$\Delta x_{i j}$ and $\Delta y_{i j}$

space coordinates of object point;

object space coordinates of perspective center; image space coordinates of principal point; measured image coordinates of point; camera constant of CCD frame $j$ (principal distance); correction terms of the image coordinates $\left(x_{i j}\right.$, $\left.y_{i j}\right)$ to be applied in order to bring the physical reality of the sensor geometry described theoretical model.

So, in the collinearity equations, beyond to internal orientation, external orientation and object coordinates of points, it is necessary to consider Additional Parameters (APs) that take into account the passage from theoretical to real model of the projection of images (internal orientation, radial and tangential distortion, etc.). A method widely used to calculate the additional parameters is proposed by Brown (1971). It consists in considering ten parameters which take into account the interior orientation of the camera, the uncertainty about the pixel shape (shape factor), a factor that consider the nonorthogonality of the reference system (shear factor), the parameters describing symmetrical radial lens distortion and the parameters of decentring lens distortion. Actually, a variety of software applications can automatically perform camera selfcalibration and, at the same time, to produce dense point clouds and/or 3D models, suitable for various applications.

The photogrammetric applications in $\mathrm{CH}$ field are rather spread, as shown in several papers (Bryan et al,1999; Beraldin, 2004; Yilmaz et al., 2007; Cowley, 2011; Pepe et al, 2016). However, to obtain an accurate survey, it is necessary to pay much attention to the survey technique. According to literature, accuracy increases with the increase in base-to-depth $(\mathrm{B} / \mathrm{D})$ ratio and using convergent images rather than images with parallel optical axes. Increasing the number of measured points per image improves the accuracy. Furthermore, the addition of images to the dataset rotated by $\pm 90^{\circ}$ to allow to improve this task (Fraser, 2001; El-Hakim et al.,2003; Remondino et al, 2006).

\subsection{Maps}

Maps systems is the set of the cartography, recent or historical, which allow to achieve the basic information needed to represent the territory. In this context, the representation of spatial information is closely related to the scale of representation (increasing scale, increasing the details of objects that must be mapping).

Historical and recent maps permit to support representation of temporal dynamics in GIS/SIS. Particularly, historical cartography all over the world is a fundamental part of Cultural Heritage, and its analogical supports regenerated in digital form permit to allow new chances of understanding and using the historical information they record (Bitelli et al, 2013). However, historical maps often present different geodetic data and/or different cartographic projections, so particular attention must be reserved to their management to obtain the correct overlay of the layers. It is almost impossible to perfectly align an old map to modern coordinate systems because mapping methods before the age of aerial photography often only very imprecisely represented scale, angle, distance, and direction (Rumsey and Williams, 2002).

An analysis may indicate the geometric reliability of information extracted for historic research (El-Hussainy et al, 2011). Several papers are available in literature for the graphical analysis of historical maps and the possibilities to overlay them to current data (Balletti and Boutoura, 2001; Livieratos, 2006; Podobnikar, 2007; Tucci and Giordano, 2011; Jongepier et al, 2016). GIS enables one to compare georeferenced historical maps with modern maps by overlaying them (Rumsey and Williams, 2002). In fact, the GIS techniques of calibration, georeferencing and transformation of projection, enable the comparison between historical and actual cartographies, permitting to reduce the effects of deformation of the media supports (paper) and those due to the different systems of representation and measurement (Baiocchi and Lelo, 2005).

\subsection{Representation}

The representation of the objects and environment of the $\mathrm{CH}$ field can be obtained using different products and solutions derived in different way, such as the vectorial feature, such as Computer-Aided Design (CAD), Esri shape file, Point Clouds, Building Information Modeling (Saygi et al., 2013) and raster information, such as ortophoto and elevation model. Following, a description of the several vector and raster format, is reported.

The $C A D$ software allows the digitization of archaeological information and, consequently in this environment, it is possible to view, measure, draw the component of the ancient world which can help to improve knowledge about the antiquity (Neamtu et al, 2011). This data structure, initially developed for mechanical engineering and architecture, is widely used due to the simplicity of drawing archaeological components. However, this structure file does not allow the management of many information. In addition, in this environment there is not any reference to the projection system and datum, while the drawing is closely related to the scale of representation.

ESRI shapefile is a format file able to overcome these limitations. It allows to store non-topological geometry and attribute information for the spatial features in a data set; the geometry for a feature is stored as a shape comprising a set of vector coordinates. The shapefile can support point, line, and area feature (Boot et al, 2001).

Another vector structure, that is spreading in $\mathrm{CH}$ field for the representation of the surveyed objects, is represented by Point Clouds (PC). Because every 3D spatial data software produces a specific format file, it follows that several format files are available, depending on the environment in which they were developed. A review of several Point Clouds format and the respective proprietary file format, is reported in the table 1 .

\begin{tabular}{|c|c|}
\hline Format file & Proprietary File Format \\
\hline E57 & ASTM \\
PTS & Leica Geosystems \\
PTX & Leica Geosystems \\
DWG & Autodesk \\
DXF & Autodesk \\
DGN & Bentley MicroStation \\
POD & Bentley Point Tools \\
ASCII & American Standard Code for Information \\
Zfs & Interchange \\
& Zoller + Fröhlich GmbH (Z+F) \\
LAS & LASer LAS File Format Exchange
\end{tabular}




\begin{tabular}{|c|c|} 
& Activities \\
LASzip & Rapidlasso GmbH \\
\hline
\end{tabular}
Table 1. Point clouds format

However, often, these formats cannot be read in some GIS software, at least that it is not an interchange file, such as the LAS format. This structure file, developed by American Society for Photogrammetry \& Remote Sensing (ASPRS), is supported by any software GIS, such as ArcMap ${ }^{\circledR}$, an ArcGIS Desktop software developed by ESRI. Each point can have additional attributes, on the specifications of the specific version of LAS format (Samberg, 2007; Pepe et al., 2015), such as intensity, class codes, and RGB color values. These attributes can be managed inside ArcGIS. Using a special tool, called " $L A S$ to Multipoint" it is possible to create multipoint features using one or more LAS files and subsequently build and manage point dataset (Esri, 2010). Furthermore, in ArcGIS environment, it is possible also view and manage 3D models in some formats, such as 3D Studio Max, SketchUp, VRML and GeoVRML, OpenFlight, and COLLADA. Indeed, in ArcScene software (3D GIS component of ArcGIS), it is possible to achieve a threedimensional view of the data points by special tool called "Create LAS Dataset".

Beyond the vector file, a type of raster representation widespread in $\mathrm{CH}$, is the othophoto. It allows, thanks to its high quality, to obtain a very intuitive and real representation of the surveyed objects and, at the same time, measure and analyse the objects under investigation. Other raster model particularly useful to describe the morphology of the area study and/or structures are Digital Elevation Model (DEM), Digital Terrain Model (DTM) and Digital Surface Model (DSM).

\subsection{Archaeological Database}

The Archaeological Database or Archaeological Database Management System is a system able for data management throughout the period of archaeological excavation projects. The Database Management System (DBMS) contains all the useful information, from initial excavation, through postexcavation analysis and research to eventual dissemination and archiving. The DBMS includes both data acquisition functions (data entry) and some processing procedures and queries. In archaeology, several DBMS are used and one of these is Microsoft Access, which is relational model (RDBMS). In Access software, the information is divided into separate tables by topic and the connection between tables are then used to join information as required (Atzeni et al., 1999).

\section{CASE STUDY}

\subsection{Area under investigation}

The area under investigation is situated in the archaeological site of Paestum (Italy). Paestum was a major ancient Greek city on the coast of the Tyrrhenian Sea in Magna Graecia (southern Italy). For this reason, archaeological remains from that period are present in this area. Among them the Paestum city walls are characterized by particular historical, architectural and archaeological interest. They represent an example of the best preserved fortification systems of Ancient Greece. Indeed, since as of today this monument is still well preserved for its entire length (about $5000 \mathrm{~m}$ ). At the cardinal points of the historical walls, there are the four main access doors: "Porta Marina" (west), "Porta Aurea" (north) "Porta Sirena" (east) and "Porta Giustizia" (south).
Following, the management of "Porta Sirena" access in SIS environment, is described (figure 1).
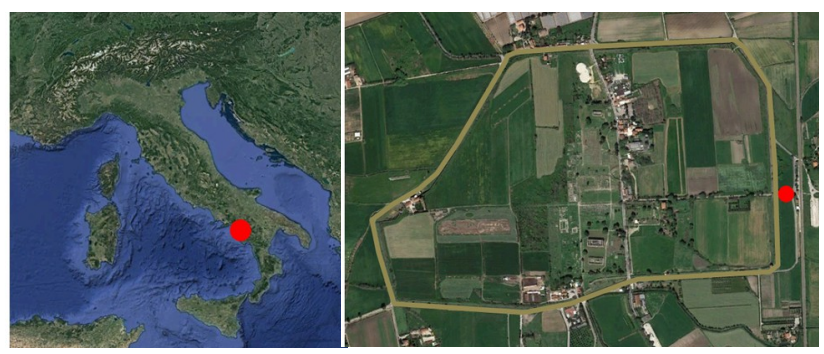

Figure 1. Archaeological site of Paestum (South-Italy)

\subsection{Data Acquisition by CRP technique}

The surveys of area study have been performed through the technique Close Range Photogrammetry in order to extraction of 3D information from images taking into account the complexity of the site (irregularity of the elevation profile of the area, requested high resolution of the model, flexibility and speed of the survey).

As regards the stage of acquisition data, the surveys have been carried out by Pentax K-x DSLR camera with $18-55 \mathrm{~mm}$ f/3.55.6 lens and a total amount of 442 images have been captured. Photogrammetric processing has been performed with Agisoft PhotoScan software. In this environment, the 3D model reconstruction is obtained in several straightforward processing steps.

After imported the photos into Photoscan software, the first step has been the alignment of images. This task allows to determinate the camera position and orientation of each photo and, at the same time, the software produces a sparse point cloud model. The "Higher accuracy" setting in the software, has allowed to obtain more accurate camera position and orientation estimations. The approach used for the alignment of the photo is the self-calibration mode.

In addition, in order to increase the accuracy of the position and orientation of the cameras and to select the effective object of the survey, on some images apposite masks have been created on the part of images that are not related to area under investigation.

Subsequently, natural element easily recognized on the photo has been chosen as marker point. The markers, equally distributed in the region of the survey, have been measured by Pentax R-325(N) total station equipped with a laser sensor for non-prism readings (figure 2 ).

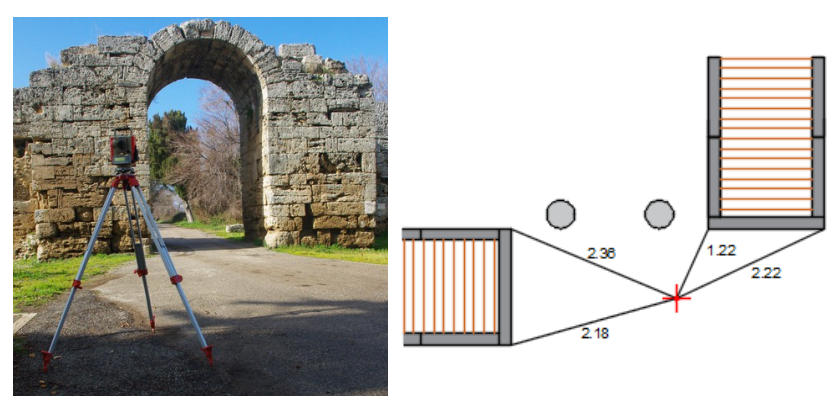

Figure 2. Total Station positioning

The adjustment of marker points, made in a local coordinate system, has been performed by using the least squares method. The coordinates of the markers have been imported into 
PhotoScan. Then, the software performs a so-called sevenparameter transformation, a transformation of set of points by rotation, scaling and translation functions. To check the quality of the survey, planimetric and altimetric errors of each marker in the three spatial coordinates have been verified. The average value of Root Mean Square (RMS) on all markers has been 16 $\mathrm{mm}$.

Once completed these operations, 3D dense coloured point clouds have been obtained. Based on the estimated camera positions the program calculates depth information for each camera to be combined into a single dense point cloud. Agisoft Photoscan software offers different options to build the dense point clouds (Low, Medium, High, Very High). The option "High" quality has been used in order to obtain more detailed and accurate geometry. Because the orientation of the structure (east-west direction), the point cloud was darker in the east while lighter on the west side of the structure. Therefore, using the algorithm developed by Pepe et al (2017) it has been possible to homogenize the colour of the entire Point Clouds. The final point clouds, constituted by about 16 million points, are shown in figure 3.

The next step has permitted to build the geometry of the object surface. Based on the dense point cloud, Photoscan software reconstructs a $3 \mathrm{D}$ polygonal mesh. A small editing, mainly direct to removal of detached components, has been performed.

Lastly, in order to obtain the orthophoto of the prospects of the structure under investigation, the meshes have been texturized. The geometric resolution of the prospect has been of $1 \mathrm{~cm}$, suitable for a scale representation 1:50.

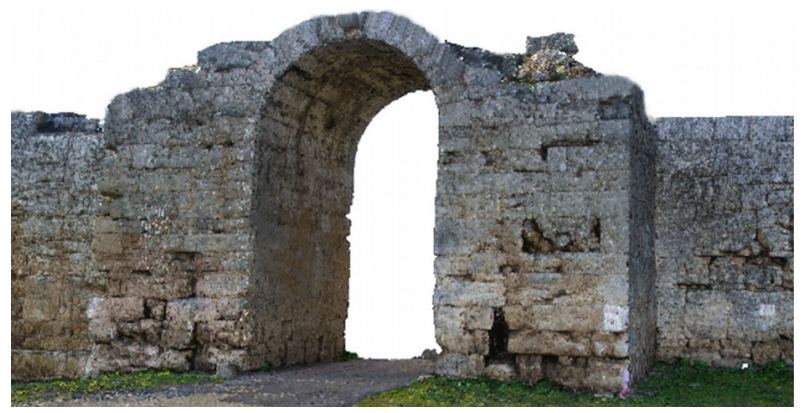

Figure 3. Point Clouds of "Porta Sirena" in north-east view

\subsection{Vector design and information system}

The step of vectorizing has been performed in Autodesk's AutoCAD software. This type of environment has allowed to draw, with accuracy and in a way quite fast, the different artefacts (figure 4). Every artefact has been recorded on a different layer by a closed polyline and, on the same layer, it is reported a unique identification code.

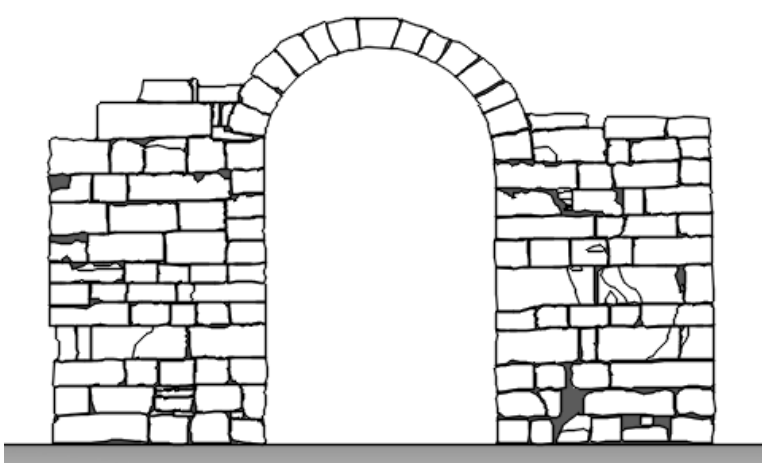

Figure 4. Vector representation in CAD environment of eastern façade of "Porta Sirena"

In order to connect the different information, it is necessary to transform the vector CAD file in Esri shape files and associate to each polygon the right identifier. This operation can be made thanks to one of the tools implemented in ArcMap ${ }^{\circledR}$. Also, the several CAD layers are transformed into a single polygon shapefile. However, the methodology of vectorizing, first in CAD environment, and subsequently, in GIS has many limits if the number of artefacts is big. Therefore, it is recommending the development of the project directly in the GIS, where Open source and owner GIS tools, especially in the last version, allows to draw the object in an environment similar to that CAD.

\subsection{SIS environment}

Every subset of SIS system involves in a specific Database. In general, each table has got a "primary key" field that identifies each object. The several tables have been connected by JOIN function. A further table, concerning the method and the operation of single survey, has been realized. Indeed, especially when the survey operations require multiple days and more operators, it is necessary to build a shape file that contains the following information:

$$
\begin{array}{ll}
\text { - } & \text { date of the survey; } \\
\text { - } & \text { operator's name; } \\
\text { - } & \text { affiliation; } \\
\text { - } & \text { technique of the survey. }
\end{array}
$$

An example of SIS environment, where the several information is shared, is shown in the figure 5.

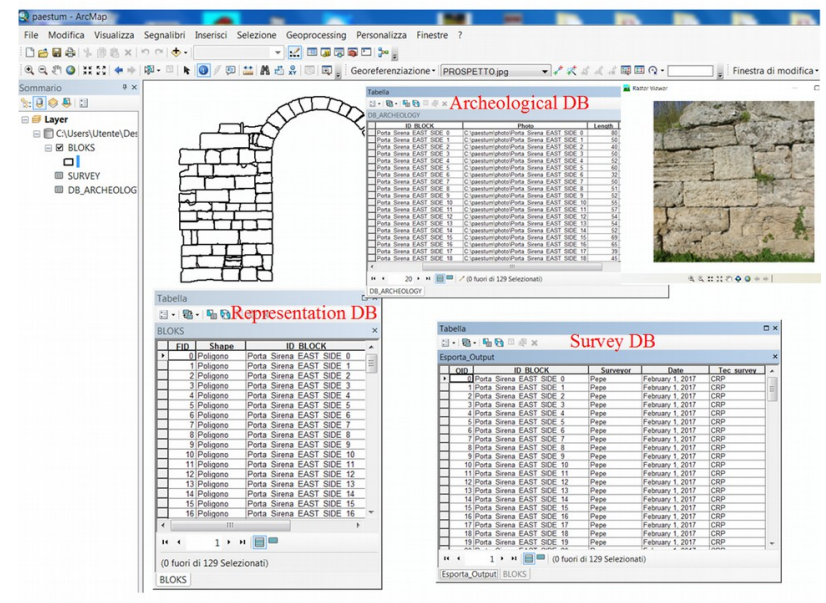

Figure 5. Several tables can be connected by join function

\section{SUMMARY AND OUTLOOK}

This paper illustrates the need of a SIS system for optimal management of the Cultural Heritage record. To accomplish this, it necessary involves more skills and of consequence, creates a team of professionals (archaeologists, architects, engineers, geomatics, etc.) to perform the architecture of the SIS (figure 6). Therefore, we can define a SIS in archaeology field and Cultural Heritage as a "set of skills and competencies that can manage the archaeological and/or Cultural Heritage data taking in account their multidimensional coordinates". 


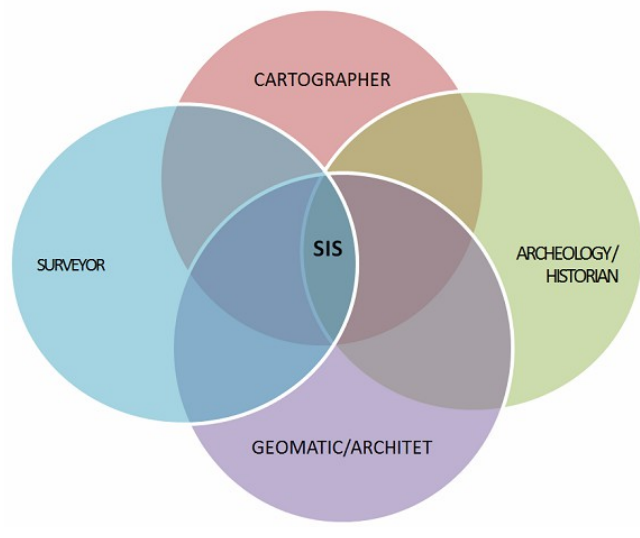

Figure 6. Skills for the construction of an archaeological and Cultural Heritage SIS

\section{CONCLUSIONS}

Methods and techniques to archive the archaeological data in SIS environment have been showed.

As regards the techniques of survey, thanks to close range approach, it is possible to obtain orthophotos, $3 \mathrm{D}$ point clouds and 3D models of high quality in terms of level of detail and accuracy. By an efficient management system, as the proposed case study shows for Porta Sirena in the archaeological site of Paestum, it is possible to observer, measure and analyse in detail an historical manufacture.

\section{REFERENCES}

Agosto, E., Ardissone, P., Rinaudo, F., 2007. GIS and WEBGIS, commercial and Open Source platforms: general rules for cultural heritage documentation. International Society for Photogrammetry and Remote Sensing and Spatial Information Sciences, 36, pp. 625-630.

Atzeni, P., Ceri, S., Paraboschi, S., Torlone, R., 1999. Database Systems: concepts, languages and architectures.

Baiocchi, V., Lelo, K., 2005. Georeferencing the historical maps of Rome between the seventeenth and eighteenth centuries. In CIPA XX International Symposium.

Balletti, C., Boutoura, C., 2001. Revisiting the projective properties of historic nautical maps of the Mediterranean and the Aegean. Mapping the 21 st century, pp. 296-302.

Beraldin, J. A., 2004. Integration of laser scanning and closerange photogrammetry-the last decade and beyond. In International Society for Photogrammetry and Remote Sensing.

Bevan, A., Conolly, J., 2013. GIS, archaeological survey, and landscape archaeology on the Island of Kythera, Greece. Journal of Field Archaeology.

Bitelli, G., Cremonini, S., Gatta, G., 2014. Cartographic heritage: Toward unconventional methods for quantitative analysis of pre-geodetic maps. Journal of Cultural Heritage, 15(2), pp. 183-195

Booth, B., \& Mitchell, A., 2001. Getting started with ArcGIS.
Brown, D.C., 1971, Close-range camera calibration, Photogrammetric Engineering, 37/8, pp. 855-866.

Bryan, P. G., Corner, I., Stevens, D., 1999. Digital rectification techniques for architectural and archaeological presentation. The photogrammetric record,16(93), pp. 399-415.

Burrough, P.A., 1986. Principles of Geographical Information Systems for Land Resources Assesment - Claredon Press, Oxford.

Cowley, D.C., 2011. Remote Sensing for Archaeological Heritage Management; EAC Occasional Paper No. 5; Occasional Publication of the Aerial Archaeology Research Group No. 3; Europae Archaeologiae Consilium: Budapest, Hungary, pp. 307.

Donadio, E., Spanò, A., 2015. Data Collection and Management for Stratigraphic Analysis of Upstanding Structures. In Proceedings of the 1st International Conference on Geographical Information Systems Theory, Applications and Management ISBN 978-989-758-099-4, pp. 34-39. DOI: $10.5220 / 0005470200340039$

El-Hakim, S., Beraldin, J., Blais, F., 2003. Critical factors and configurations for practical 3D image-based modeling. In: 6 th Conference on Optical 3D Measurements Techniques, Zurich, Vol.2, pp.159-167.

El-Hussainy, M. S., Baraka, M. A., El-Hallaq, M. A. (2011). A methodology for image matching of historical maps. $e$ Perimetron, 6(2), pp.77-95.

ESRI. 2010. Lidar Analysis in ArcGIS 9.3.1 for Forestry Applications White Paper Esri, 380 New York St., Redlands, CA 92373-8100 USA

https://www.esri.com/library/whitepapers/pdfs/lidar-analysis-

forestry.pdf

(Last Accessed: February 13, 2017)

Fraser, C.S., 2001. Network design. In Close Range Photogrammetry and Machine Vision (K.B. Atkinson Ed.), Whittles Publishing, Caithness, Scotland, U.K.

Gomarasca, M.A., 2009, Elements of Remote Sensing, Basics of Geomatics, Milan, Italy: Springer, pp 123-171.

Grün, A., Beyer, H., 2001. System calibration through selfcalibration. In: A. Grün, \& T. S. Huang (Eds.), Calibration and orientation of cameras in computer vision, Berlin, Germany: Springer, pp. 163-193.

He, J., Liu, J., Xu, S., Wu, C., Zhang, J., 2015. A GIS-Based Cultural Heritage Study Framework on Continuous Scales: A Case Study on 19th Century Military Industrial Heritage. The International Archives of Photogrammetry, Remote Sensing and Spatial Information Sciences, 40(5), 215.

Hosse, K., Schilcher, M., 2003. Temporal GIS for analysis and visualization of cultural heritage. In Proceedings of CIPA XIX international Symposium, Commission V, WG5, Antalya.

Hugo, G., 2000. How can spatial information systems assist in the fight against HIV/AIDS. In National Symposium on "Every Eight-Seconds: AIDS Revisited" organized by the National 
Academies Forum and the National Library of Australia, National Library Theatre, Canberra, pp. 29-30.

Jongepier, I., Soens, T., Temmerman, S., \& Missiaen, T., 2016. Assessing the Planimetric Accuracy of Historical Maps (Sixteenth to Nineteenth Centuries): New Methods and Potential for Coastal Landscape Reconstruction. The Cartographic Journal, 53(2), pp. 114-132.

Karara, H. M., 1989. Non Topographic Photogrammetry. Asprs, Falls Church, Virginia. Isbn-0-944426-23-9.

Livieratos, E., 2006. On the study of the geometric properties of historical cartographic representations. Cartographica: The International Journal for Geographic Information and Geovisualization, 41(2), pp. 165-176.

Maguire, D. J., 1991. An overview and definition of GIS. Geographical information systems: Principles and applications, 1, pp. 9-20.

Neamtu, C, Popescu, D, Mateescu, R, 2011. From classical to 3D archaeology, Annales d'Universite "Valahia" Târgovite, Section d'Archeologie et d'Histoire , XIII, 1, 2011, pp. 79-88.

Pepe, M., Ackermann, S., Fregonese, L., and Achille, C, 2017. New Perspectives Of Point Clouds Color Management - The Development Of Tool In Matlab For Applications In Cultural Heritage, Int. Arch. Photogramm. Remote Sens. Spatial Inf. Sci., XLII-2/W3, pp. 567-571, doi:10.5194/isprs-archives-XLII2-W3-567-2017.

Pepe, M., Prezioso, G., 2015. A Matlab geodetic software for processing Airborne Lidar Bathymetry data, Int. Arch. Photogramm. Remote Sens. Spatial Inf. Sci., XL-5/W5, pp. 167-170, doi:10.5194/isprsarchives-XL-5-W5-167-2015.

Podobnikar, T., 2007. Characteristics of the positional errors of historical maps. In 10th AGILE International Conference on Geographic Information Science-Aalborg University, Denmark.

Remondino, F., Fraser, C., 2006. Digital camera calibration methods: Considerations and comparisons. Int. Arch. Photogramm. Remote Sens. Spat. Inf. Sci.2006, 36, pp. 266272.

Remondino, F., 2011. Heritage recording and 3D modeling with photogrammetry and 3D scanning. Remote Sensing, 3(6), pp. $1104-1138$.

Rumpler, M., Daftry, S., Tscharf, A., Prettenthaler, R., Hoppe, C., Mayer, G., Bischof, H., 2014. Automated End-to-End Workflow for Precise and Geo-accurate Reconstructions using Fiducial Markers. ISPRS Annals of Photogrammetry, Remote Sensing and Spatial Information Sciences, pp. 135-142.

Rumsey, D., Williams, M. 2002. Historical maps in GIS Chapter 1 in: Knowles, A. K., Past time, past place: GIS for history.

Samberg, A., 2007. An implementation of the ASPRS LAS standard. In ISPRS Workshop on Laser Scanning and SilviLaser, pp. 363-372.
Sansoni, G., Trebeschi, M., Docchio, F., 2009. State-of-the-art and applications of 3D imaging sensors in industry, cultural heritage, medicine, and criminal investigation. Sensors, 9, pp. 568-601

Saygi, G., Remondino, F., 2013. Management of Architectural Heritage Information in BIM and GIS: State-of-the-art and Future Perspectives. International Journal of Heritage in the Digital Era, 2(4), pp. 695-713.

Tucci, M., Giordano, A. 2011. Positional accuracy, positional uncertainty, and feature change detection in historical maps: Results of an experiment. Computers, Environment and Urban Systems, 35(6), pp. 452-463.

Yilmaz, H. M., Yakar, M., Gulec, S. A., Dulgerler, O. N., 2007. Importance of digital close-range photogrammetry in documentation of cultural heritage. Journal of Cultural Heritage, 8(4), pp. 428-433. 